\title{
CONSTRAINTS ON CHEMICALLY MEDIATED COEVOLUTION: MULTIPLE FUNCTIONS FOR SEAWEED SECONDARY METABOLITES ${ }^{1}$
}

\author{
Tim M. SchMitT, MARK E. HAy, ${ }^{2}$ AND NiEls Lindquist \\ University of North Carolina at Chapel Hill, Institute of Marine Sciences, Morehead City, North Carolina 28557 USA
}

\begin{abstract}
Diterpene alcohols produced by the brown seaweed Dictyota menstrualis deter feeding by numerous species of abundant herbivores. Here we show that these same compounds also may prevent fouling organisms from colonizing the surface of this alga. In the field, Dictyota menstrualis plants were less frequently and less heavily fouled than any of the other common seaweed species investigated. In laboratory assays, larvae of the common fouling bryozoan Bugula neritina failed to settle on Dictyota even though they contacted its surface as often as they contacted the surface of a preferred host alga. Rejection occurred only after direct contact with the alga's surface. Rejection of Dictyota was not mediated by water-borne chemical cues or by surface wettability (a physical property of the surface that can affect fouling). The lipid-soluble extract from surface rubbings of Dictyota inhibited larval settlement when placed on other surfaces and contained the diterpene alcohols pachydictyol A and dictyol E. Larvae exposed to these compounds experienced mortality, abnormal development, or reduced rates of development.

Although the potential for chemically mediated coevolution between plants and herbivores has been the focus of scores of previous investigations, such coevolution will depend on selection altering the chemical defenses of the plant following the evolution of resistance by herbivores. Such a reciprocal response will be constrained if compounds play multiple roles that are ecologically important. Dictyota produces secondary metabolites that are broadly defensive against a wide variety of consumers and fouling organisms. Although certain consumers may evolve resistance to these metabolites, it is unclear that feeding by these consumers will result in reciprocal responses from the plant. We suggest that coevolved interactions may be uncommon, and that many interactions that appear to be coevolved may result from fortuitous and opportunistic preadaptations.
\end{abstract}

Key words: allelopathy; antifouling; chemical defense; coevolution; Dictyota; plant-herbivore interactions; seaweed; secondary metabolites.

\section{INTRODUCTION}

There has been a long and sustained interest in coevolution (Ehrlich and Raven 1964, Futuyma and Slatkin 1983, Spencer 1988, Thompson and Burdon 1992) with much of this interest focused on chemically mediated plant-herbivore interactions. There is, however, still considerable debate over the relative importance of coevolution in (1) shaping characteristics of either the plant or herbivore (Fox 1981, Vermeij 1983, 1992, Strong et al. 1984, Bernays and Graham 1988, Estes and Steinberg 1988, Spencer 1988, Futuyma and McCafferty 1990, Steneck 1992, Singer and Parmesan 1993), (2) the role that herbivores, especially insects, play in selecting for plant chemical defenses (Futuyma 1983, Jermy 1984, Bernays et al. 1989, Crawley 1989, Hay and Steinberg 1992, Steneck 1992, Hay et al. 1994), and (3) the possible alternative or additional functions that secondary plant metabolites may have as allelopathic or antimicrobial agents (Bernays et al. 1989, Paul 1992). Most investigations in terrestrial sys-

\footnotetext{
${ }^{1}$ Manuscript received 20 September 1993; revised 2 May 1994; accepted 3 June 1994.

${ }^{2}$ Send reprint requests to this author.
}

tems focus on plant-insect interactions and assume that secondary metabolites evolved primarily as deterrents against insect feeding (Ehrlich and Raven 1964, Rosenthal and Janzen 1979, Denno and McClure 1983, Strong et al. 1984, Coley et al. 1985, Spencer 1988, Coley and Aide 1990, Rosenthal and Berenbaum 1992). In contrast, some marine investigators (see reviews in Paul 1992) and a few investigators of terrestrial systems (Zucker 1983, Bernays et al. 1989, Thompson and Burdon 1992) have noted that secondary metabolites that deter feeding by herbivores could also serve other functions. This possibility has not been tested directly for marine plants.

If individual secondary metabolites play multiple functional roles, then pairwise coevolution, mediated via plant chemical defenses, is less likely to occur between individual plant and herbivore species because plants will be constrained by these other functional roles from changing their secondary metabolites in response to the evolution of resistance by particular herbivores. Even if we relax the constraints that would apply to pairwise coevolution and consider the potentially broader role of diffuse coevolution (Fox 1981) between a plant and the cumulative damage it expe- 
riences as a result of attack by all herbivores, the importance of this less constrained interaction in driving plant chemical defenses will be more limited if metabolites play multiple roles that are ecologically important.

The relative impact of herbivory vs. fouling in selecting for chemical defenses in marine habitats is unclear. Herbivory has been demonstrated to have strong effects on seaweed populations and communities in a wide variety of marine habitats (Lubchenco and Gaines 1981, Hay 1985, 1991a, John et al. 1992). Effects of fouling are less well studied, but fouling can reduce growth and reproduction of host seaweeds (Orth and van Montfrans 1984, Brawley 1992, Williams and Seed 1992), cause increased drag and thus losses of host seaweeds during storms (see examples in Brawley 1992, Williams and Seed 1992), and increase tissue loss to grazers that are attracted to hosts because of their associated fouling organisms (Bernstein and Jung 1979).

In this study, we show that the diterpene alcohols that defend the brown seaweed Dictyota menstrualis from herbivorous fishes and urchins also can serve as allelopathic agents that damage the larvae of fouling organisms and prevent the alga from being overgrown. We argue that the broad ecological roles of these metabolites as both herbivore defenses and allelopathic agents will constrain alterations of the plant's chemical defenses in response to the evolution of resistance by particular species of herbivores or fouling organisms. If plant secondary metabolites commonly serve multiple functions, then coevolved interactions may be less common than is generally thought, and interactions that appear to be coevolved often may result from fortuitous preadaptations that are opportunistically coopted for other uses (see Gould and Lewontin 1979, Gould and Vrba 1982 for expansion on this theme). Recent studies in both marine and terrestrial communities provide evidence suggesting that this view deserves more attention (Steneck 1992, Thompson and Burdon 1992, Vermeij 1992).

\section{METHODS}

Fouling in the field.-To compare fouling of Dictyota menstrualis to that of other algae, collections were made at Radio Island Jetty, near Beaufort, North Carolina, between 2 October and 7 November 1991. A $60 \mathrm{~m}$ long tape marked at random intervals was placed along the jetty at a depth of $\approx 1 \mathrm{~m}$ below mean low tide. At each of 21 randomly marked positions, individual plants of the common brown algae Dictyota menstrualis, Sargassum filipendula, and Padina gymnospora, and the common red algae Gracilaria tikvahiae, Chondria dasyphylla, and Rhodymenia pseudopalmata were collected and placed together in a plastic bag. At each sampling location, the individual of each species that was closest to the tape was collected; however, because some species (particularly Gracilaria) were rare at places along our transect, a larger area not immediately adjacent to the sampling point sometimes had to be searched. In these instances, the first plant encountered was collected. Agardhiella subulata (a species used in some assays described below) was not included in these collections because it was not present on the jetty while we were collecting.

By making collections in October and November when Dictyota menstrualis was near the end of its growing season, we may have biased our results in favor of increased abundance of fouling organisms on Dictyota. It is our subjective impression, based on several years of working with Dictyota, that it is virtually epiphyte-free during most of the growing season but occasionally becomes fouled in the fall as it approaches senescence.

Seaweeds from these field collections were returned to the laboratory, fouling organisms large enough to be seen without magnification were removed from the alga with forceps, identified, and placed in a drying oven for several days at a temperature of $60^{\circ} \mathrm{C}$ (as was their seaweed host). Before drying, the projected surface areas of 5-9 individuals of each algal species were measured to the nearest $0.001 \mathrm{~cm}^{2}$ with a LI-COR 3100 surface area meter. Mean projected surface area per dry mass was calculated for each species and used to convert dry mass measurements to algal surface area (we assumed that fouling of seaweeds was related more to surface area than to mass). The dry mass of fouling organism per algal surface area was then calculated for each individual alga. Because these data were not normally distributed, we could not use a standard ANOVA to test for among-species differences in fouling mass per surface area of alga. Therefore, each datum was ranked from most to least fouled, and a one-way ANOVA was run on these ranks. This test is equivalent to the Kruskal Wallis $k$-sample test, but is often more powerful (SAS 1985: 651). This procedure was also used to assess differences among algal species in fouling by bryozoans, epiphytic algae, tube-building animals, and sponges. In addition, the frequency with which seaweed species were fouled vs. not fouled were assessed by a $G$ test using Sidak corrections for multiple comparisons. Because these frequencies might be affected by mean plant size (i.e., larger plants have more surface area and greater potential for fouling), we also assessed among-species differences in surface area of the collected plants and analyzed these by ANOVA followed by Student-Newman-Keuls (SNK) tests.

Fouling in laboratory assays. - To determine if low usage of Dictyota by fouling organisms could result from larval settlement behavior, approximately equal surface areas of each of seven algal species (Dictyota menstrualis, Padina gymnospora, Sargassum filipendula, Gracilaria tikvahiae, Agardhiella subulata, Chondria dasyphylla, and Rhodymenia pseudopalmata) were placed in $1.5-\mathrm{L}$ glass bowls filled with seawater (i.e., all seven algal species were placed in each 
of the 13 bowls). More than 100 larvae of the common bryozoan Bugula neritina were then pipetted into each bowl. We considered this bryozoan to be a good assay organism because: (1) it was the most abundant fouling organism on most of the algae we collected from the field, (2) it commonly grows on seaweeds, benthic invertebrates, and a wide variety of hard substrates, and (3) it is widespread, abundant, and co-occurs with the seaweeds used in our assays. Because the larvae settled quickly, we could not take the time to count out exact numbers of larvae for each replicate bowl $(N=13)$; instead, we added larvae as equal volume aliquots from a concentrated batch. Although we used a precise volume plankton sampler to take our aliquots and tried to homogenize the density of larvae within the batch container by shaking it between aliquot withdrawals, we still found large among-replicate variance in the number of larvae in each container. We have therefore usually presented our results as percentages, rather than numbers, of larvae on each substrate.

After $24 \mathrm{~h}$, the number of Bugula larvae settled on each alga was counted using a dissecting microscope. The projected surface area of each alga was determined using the LI-COR area meter, and settlement densities (i.e., larvae per square centimetre) were calculated for each alga in each bowl. The relative density of larvae on each alga in each bowl was then calculated by dividing the density for each alga by the summed density for all the algae in that bowl. Assuming random settlement, the expected density of larvae on each alga in each bowl could be calculated by dividing the summed settlement density for each bowl by 7 , the number of algal substrata present (thus, expected values varied between bowls due to differences in larval numbers, sizes of the plants, and numbers of larvae settling, but all plants within a bowl had equal expected densities). By analyzing differences between observed and expected values of settlement for each algal species (using a paired $t$ test), we could determine which seaweeds were repellent to, attractive to, or used indiscriminately by Bugula larvae under these conditions. In order to keep the experiment-wise error rate $(\alpha)$ at .05 across the seven comparisons, an adjusted alpha $(\alpha=.0085)$ was calculated by Dunn-Sidak's method (Sokal and Rohlf 1983: 242). These assays were context dependent because larvae had simultaneous access to each of our seven algal species (e.g., algal species were not independent because high settlement on one species would result in lower numbers of larvae available to settle on the other species). Although this design approximates the numerous simultaneous choices that larvae might have in the field, it prevents using an ANOVA-type analysis to evaluate among-species differences in the density of larvae settling on each alga because our treatments (=algal species) are not independent (see Peterson and Renaud 1989 for a discussion). We therefore used a $G$ test to evaluate among-species differences in the number of replicates in which an algal species was colonized by at least one larva vs. not colonized at all. Unlike the ANOVA, this procedure does not require independence of treatments.

To determine if the low epiphyte abundance on field collections of Dictyota and the reluctance of Bugula larvae to settle on Dictyota in the laboratory assays could have been due to water-borne metabolites released by the alga, we placed Bugula larvae in seawater taken from the center of clumps of Dictyota during slack tide and compared the behavior and settlement of these larvae with those placed in water taken from $>1 \mathrm{~m}$ away from any Dictyota plant. During slack high tide at Radio Island Jetty, $10-\mathrm{mL}$ polystyrene syringes were inserted close to the fronds $(<0.5 \mathrm{~cm})$ in clumps of Dictyota, and $10 \mathrm{~mL}$ of seawater were drawn into the syringe. The syringe was capped to prevent leakage, and a paired control syringe was filled in the nearby water column but away from Dictyota. Nineteen pairs of syringes were filled, returned to the laboratory, and immediately discharged into tripartitioned polystyrene petri dishes. The individual chambers in these dishes will hereafter be called partitions. Bugula larvae were then added to each partition in each dish. Settlement onto the polystyrene was checked after $1 \mathrm{~h}$, and again after $\approx 24 \mathrm{~h}$. Differences in settlement between larvae in water from near Dictyota vs. water collected at a distance from Dictyota were analyzed by a paired $t$ test. One replicate that had only three settled larvae was excluded from the analysis, resulting in $N=18$.

In this and the following experiments, replicates were excluded from analysis if the number of larvae settling was so low that percentages were subject to an unacceptably high potential random error. Excluded replicates will be noted in the text.

Because water from within clumps of Dictyota had no effect on larval survival or settlement, we suspected that rejection of Dictyota as a settlement surface may have been due to properties sensed by the larvae following direct contact with the alga's surface. To test this, 30-100 Bugula larvae were added to each of 13 300-mL bowls containing approximately equal-sized pieces of Dictyota menstrualis and Gracilaria tikvahiae (the latter species is a high preference substratum for Bugula). The number of larvae contacting each alga within 2 min was counted for a section of each alga framed in the lowest field of vision ( $6 \times$ magnification) of a dissecting microscope. In an effort to achieve independence of observations, larvae that did not leave the viewing field before contacting the alga again were scored as having made only one contact with the alga. However, because individual larvae could not be distinguished, larvae that left the viewing field and then returned to contact the alga may have been counted more than once. The other alga in that bowl was then observed for $2 \mathrm{~min}$. The algal species that was observed first was alternated between replicates. After counting larval contacts for both algae, the portion of each alga in the viewing field was excised from the rest of the 
plant and its surface area was measured. The number of contacts per surface area was calculated for each alga in each replicate, and the differences between contacts with each alga were analyzed by the paired $t$ test.

In order to increase the resolution of any differences between treatments, replicates that had less than 10 total contacts of larvae with algae were excluded from analysis. This reduced the number of replicates from 13 to 10 . Following the observations of larval contact, bowls were covered and larvae were allowed to settle on the algae remaining in each bowl. The next day, the number of individuals settled on each alga was counted for each replicate.

Assays of Dictyota secondary metabolites. - The above assay showed that larvae contacted Dictyota and Gracilaria with equal frequency but settled almost exclusively on Gracilaria. This lead us to investigate properties of Dictyota's surface that might be affecting larval settlement. Two experiments were run in an attempt to document the presence or absence of secondary metabolites on the surface of Dictyota. In both assays, individual Dictyota plants were collected at Radio Island Jetty and immediately placed in separate plastic bags filled with ambient seawater. Plants were handled as little as possible during collection. Upon returning to the laboratory, excess water was removed from individual plants by spinning them for several revolutions in a salad spinner. Plants were then laid flat on a paper towel, and the upper side was rubbed gently with cotton swabs. The tips of the swabs were then removed and extracted for several hours in a $1: 1 \mathrm{mix}-$ ture of dichloromethane: methanol.

Individual plants were then dried in a drying oven at $60^{\circ} \mathrm{C}$ for several days. Surface areas of the plants were estimated from dry mass : surface area ratios calculated for each experiment from portions of plants used in that assay $(N=4$ replicate ratios for the first assay described below, and $N=10$ for the second assay described below).

Extracts from the swabs were analyzed by analytical high performance liquid chromatography to search for the presence of known Dictyota secondary metabolites. Extracts were first rotary-evaporated to dryness and then dissolved in hexane. The hexane soluble materials were placed onto a 500-mg florisil column and rinsed twice with several millilitres of hexane to elute nonpolar compounds. This fraction was discarded. Known secondary metabolites were eluted with two rinses of 65:35 hexane : diethyl ether. These combined fractions were evaporated to dryness under nitrogen and then freeze dried for $20 \mathrm{~min}$ to remove residual solvent. The extract was dissolved in $50 \mu \mathrm{L}$ of 9:1 trimethylpentane (=TMP) : ethyl acetate. One HPLC injection was made for each sample. An elution solvent of 9:1 TMP : ethyl acetate at a flow rate of $0.85 \mathrm{~mL} / \mathrm{min}$ produced an effective separation of the Dictyota metabolites by HPLC. Peaks eluted at 2.3 and $7.7 \mathrm{~min}$ (expected to be the diterpene alcohols pachydictyol A and dictyol
E, respectively, based on triplicate injections of standards) were each collected and pooled for all of the HPLC runs. These collected peaks were analyzed by high resolution electron impact mass spectrometry to confirm their molecular formulas.

In the second assay, plants were collected and swabbed as described above. The extract from the swabs was evaporated to dryness by rotary-evaporation. The dichloromethane soluble portion of this extract was dried under a stream of nitrogen and diluted with ethanol to a volume such that $50 \mu \mathrm{L}$ of solution would hold the extract swabbed from $9.91 \mathrm{~cm}^{2}$ of plant surface. This surface area was equal to one-half of one of the partitions in our settling dishes. Because polystyrene is an ideal substratum for Bugula settlement (Maki et al. 1989), we used tri-partitioned polystyrene petri dishes as our settling chambers. By coating onehalf of each of these three partitions with Dictyota surface extract and the other half with a control solution (ethanol only), we were able to perform a settlement choice assay. To coat extract onto portions of our settlement dishes, we dispersed $50 \mu \mathrm{L}$ of solution through a Wiretrol pipette. To enhance the evenness of the coat, the end of the pipette was fitted with a porous chromatographic disc removed from a Sep Pak florisil column. The disk was kept saturated with solution so that as the solvent and extract were dispensed, they spread through the disk and produced a thin, even coat on the plate. After the treatment side of each partition had dried, the control side was coated with extract from the Sep Pack filters (preliminary experiments had shown settlement to be unaffected by extracts of the cotton swabs-49\% of larvae settled on the swab-treated side and $51 \%$ settled on the control side, $P=0.76, N=$ 15, paired $t$ test). The settlement plates were then placed in a freeze dryer for $20 \mathrm{~min}$ to remove any residual solvents, and $6 \mathrm{~mL}$ of unfiltered seawater were added to each partition. Fifteen to 20 Bugula larvae were then added to each partition. Settlement on the treatment vs. the control side of each partition was observed after $1 \mathrm{~h}$. Differences in settlement were analyzed by a paired $t$ test. Three replicates were excluded from analysis because of low settlement (less than seven larvae settled); this resulted in $N=22$.

The tests described above indicated that pachydictyol $\mathrm{A}$ and dictyol $\mathrm{E}$ were present in surface rubbings of Dictyota and that extracts of these rubbings deterred settlement of Bugula larvae when coated onto polystyrene surfaces. Because the amounts of Dictyota secondary metabolites contained in the small samples of surface rubbings used in the settlement experiments described above were below the concentrations we could reliably measure using analytical HPLC, we could not quantify their concentration in the extracts or monitor their fates when they were in crude extracts and coated onto our polystyrene dishes. Although HPLC analyses of these small extract samples produce peaks that can be identified as pachydictyol $\mathrm{A}$ and dic- 
tyol E, at these low concentrations, we are not confident that most of the compounds are not being lost on glassware and columns during preparation of the samples for HPLC. For this assay, HPLC could thus be used reliably to determine presence of the compounds, but not to quantify their concentrations.

To try and achieve some understanding of whether these compounds stayed on the polystyrene surfaces or dissolved into the water column, we ran the following two experiments. In the first, nine polystyrene petri dishes were coated (as described above for the assays with crude extracts) with $50 \mu \mathrm{L}$ of ethanol containing $50 \mu \mathrm{g}$ of pachydictyol $\mathrm{A}$. The dishes were allowed to air dry and any residual solvent was removed by placing the dishes under high vacuum in a freeze dryer for $2 \mathrm{~min}$. Ten millilitres of seawater were then added to each dish, and dishes were allowed to sit for $1 \mathrm{~h}$. In the second experiment, nine petri dishes were filled with $10 \mathrm{~mL}$ of seawater and the ethanol and pachydictyol A were dispersed into the seawater rather than being coated onto the dish surface. After $1 \mathrm{~h}$, the seawater from each petri dish in each experiment was pipetted off and extracted 3 times with dichloromethane. Each petri dish surface was then extracted 3 times with ethanol. We used ethanol for dish extractions because dichloromethane would dissolve the polystyrene dishes; we used dichloromethane for the water extractions because dichloromethane separates from water and allows the lipophilic compounds to be partitioned out of the water and into this organic solvent (ethanol would have mixed with the water). The extract from each dish (i.e., $N=9$ for each assay) was dried under nitrogen, diluted to a known volume, and the concentration of pachydictyol $\mathrm{A}$ in each was determined by analytical HPLC.

Because compounds coated onto the surface of the polystyrene dishes were not released into the seawater in the dishes and because larvae would leave surfaces coated with Dictyota extracts, larvae placed in dishes treated by coating their surface could avoid exposure to the compounds by refusing to settle (i.e., behaviorally avoiding exposure). Thus, using coated plates to determine the potential physiological effects of the compounds on larvae or settled juveniles staying in contact with a treated surface was not possible. However, because $\approx 50 \%$ of the pachydictyol A placed into seawater (rather than on dish surfaces) remained in the seawater, we could measure the physiological effects of Dictyota secondary metabolites on Bugula larvae by placing larvae in polystyrene dishes filled with seawater containing various concentrations of pachydictyol $\mathrm{A}$ or dictyol $\mathrm{E}$ that had first been dissolved in a carrier solvent that was miscible in water (i.e., we prevented larvae from behaviorally avoiding exposure to the metabolites). Larval settlement and development on the polystyrene were then monitored for 67-72 h.

In assays reported here, compounds were dissolved in ethanol so that $100 \mu \mathrm{L}$ of the solution added to 10
$\mathrm{mL}$ of unfiltered seawater would yield the desired test concentration. It is presently impossible to determine the concentration of secondary metabolites a larva would experience when settling onto the surface of Dictyota. Determining this involves at least the following obvious limitations: (1) lipophilic compounds like the dictyols may smear across the surface of Dictyota rather than being effectively absorbed onto our cotton swabs (e.g., cleaning oil off a slick surface with a cotton swab is ineffective) - this may mean that our initial assays with surface extracts were run at unnaturally low concentrations, (2) even though we swabbed plants gently, we could have ruptured surface cells and collected dictyols that were in, rather than on, Dictyotathis may mean that our assays with surface extracts were run at unnaturally high concentrations, (3) both problems (1) and (2) could occur, leaving us uncertain how our assay concentrations relate to natural concentrations, and (4) when larvae contact a surface holding a bioactive compound, it is unclear how much compound will be moved into the larvae where basic physiological processes could be affected. Given these limitations, we chose to test a large range of concentrations so we could see what effects the compounds had on Bugula and document how this varied as a function of concentration. Seven concentrations of each compound were individually tested: $10,5,1,0.5,0.1,0.01$, and 0 (solvent control) $\mu \mathrm{g} / \mathrm{mL}$.

Compounds were isolated from Dictyota by silicagel vacuum-flash chromatography followed by silicagel HPLC. They were identified by nuclear magnetic resonance spectroscopy (NMR) and other spectrographic techniques by $\mathrm{W}$. Fenical and colleagues at Scripps Institution of Oceanography.

After being placed in our assay dishes, larvae were allowed to settle and grow in the dark. Settlement and development were checked after $1 \mathrm{~h}$ and at intervals of 18-24 h thereafter. Experiments were terminated on the 3rd d after larval addition. Larval development was recorded as follows: individuals were scored as either dead, swimming, on the bottom but not settled, settled, settled and metamorphosed, metamorphosed with one zooid, metamorphosed with two zooids, or metamorphosed and dead. In the case of pachydictyol A, many individuals settled and began to develop but were deformed; this was recorded as well. No individuals developed beyond the two-zooid stage during the course of these experiments. Differences in larval development or mortality at each observation period were analyzed by ANOVA and SNK tests.

Surface wettability of the seaweeds.-Attachment of larvae to surfaces can be mediated by surface wettability (the tendency of a surface to cause water to spread over, vs. bead-up on, its surface, Baier 1970). Differences in the wettability of surfaces may therefore play a large role in the settlement behavior of some invertebrate larvae (Rittschof and Costlow 1989, Pawlik 1992), and this characteristic could conceivably have 
caused the avoidance of Dictyota that we noted in our field and laboratory assays. To see if among-algal differences in surface wettabilities, which are measured as contact angles of surfaces with water, could explain the avoidance of Dictyota by Bugula larvae, algal surface wettabilities were measured using a Cahn DCA312 dynamic contact angle analyzer. Ten individuals each of Gracilaria tikvahiae, Chondria dasyphylla, Rhodymenia pseudopalmata, Dictyota menstrualis, Sargassum filipendula, and Padina gymnospora were collected from Radio Island Jetty. Agardhiella subulata, which was not present at Radio Island when we conducted this assay, was collected from grassbeds near Harker's Island, North Carolina. Plants were held in flowthrough seawater tanks until analyzed (within 1-2 d of collection).

In preparation for analysis, a portion of each plant was cut out and the perimeter of its cross section measured to within $0.05 \mathrm{~mm}$ with a caliper. For flattened species (Dictyota, Sargassum blades, Padina, Gracilaria, and Rhodymenia), the width and thickness of the segments were recorded. Dictyota, Sargassum blades, Padina, and Rhodymenia are very thin, so their thickness was assumed to have little effect on their perimeter measurement, and their perimeter was estimated to be twice their width. Gracilaria thickness was measured at its widest point, and its compressed, oval-shaped cross section was assumed to be a rectangle (i.e., perimeter $=($ width + thickness $) \times 2$ ). This procedure would slightly overestimate its perimeter. For plants that were round in cross section (Chondria and Agardhiella), segments of constant diameter were excised from the plant, stripped of side branches, and the measured diameter of the segment was multiplied by $\pi$ to obtain the perimeter.

Algal segments were hung from a balance above a movable beaker of seawater. As the stage holding the beaker moved up, the seawater contacted the alga and was moved past it. The changing force on the balance due to the water moving past the suspended alga was recorded once per second as the stage moved up and then back down. The contact angle of water molecules with the algal surface was then determined as the integrated product of the contact angles generated by the formula $F=\mathrm{ST} \times P \times \cos Q / 0.981$ where $F=$ sample force at 0 immersion depth as measured by the balance (in milligrams); ST = surface tension of the immersing liquid (dynes per centimetre); $P=$ the perimeter of the sample at the interface (in centimetres); and $\cos Q=$ the cosine of the contact angle (for an elaboration of these methods, see Gerhart et al. 1992). Advancing (stage moving up) and receding (stage moving down) contact angles were calculated for each replicate. Among-species differences in contact angles for the algae were analyzed separately for advancing and receding contact angles by ANOVA/SNK. To test for a predictable relationship between algal surface wettabilities and Bugula settlement, we regressed mean set- tlement on the different seaweed species against their mean wettabilities.

\section{RESULTS}

Fouling in the field.-Field collections showed that the frequency of fouling and the mass of fouling organisms per square centimetre of algal surface was significantly less on Dictyota than on any of the other seaweeds investigated (Fig. 1). Only 10\% (2 of 20) of the Dictyota plants were fouled by any macroorganism, while $48-95 \%$ of the individuals of other seaweed species were fouled (Fig. 1). This reduced frequency of fouling for Dictyota was documented even though the mean surface area of Dictyota plants (i.e., the area available for colonization) was 2.6-7.2 times the surface area of the more heavily fouled seaweeds (Padina, Chondria, Gracilaria, and Rhodymenia). This would have biased our data toward greater, not lesser, frequencies of fouling for Dictyota.

The most abundant organisms that fouled seaweeds were bryozoans, other algae, various tube-building animals, and sponges (Fig. 2). Organisms other than these accounted for only $1.2 \%$ of the dry mass of macroscopic fouling organisms found on the seaweeds. The bryozoan Bugula neritina was found on all algal species and was the only fouling species found on Dictyota, occurring on 2 of the 20 plants. Discounting sponges, which were restricted almost exclusively to Rhodymenia (Fig. 2), bryozoans made up $45 \%$ of the mass of organisms attached to seaweeds; algae comprised $31 \%$ and tube-building animals 23\%. Bryozoans were significantly less abundant on Dictyota than on any of the other seaweeds (Fig. 2). Dictyota was less fouled by algae than were any of the other species; these differences between Dictyota and the other seaweeds were significant for all contrasts with the exception of Padina. Although the one-way ANOVA run on among-species differences in the ranks of fouling by tube-building animals was significant $(P=0.019)$, additional analyses (SNK) failed to detect where these differences occurred. Dictyota was, however, fouled less by tube builders than were the other seaweeds. Sponges occurred only on Rhodymenia and Chondria with the abundance on Rhodymenia being $\approx 370$ times greater than that on Chondria (Fig. 2).

We did not investigate why Gracilaria tended to be fouled more than other seaweeds by algae and bryozoans or why Rhodymenia tended to be more fouled by sponges and tube-building animals. However, we found Rhodymenia primarily on shaded vertical surfaces where animals tend to be more common than plants (Hay and Sutherland 1988); growth in this microhabitat may have favored fouling by sponges and tube-building animals. The tendency for Gracilaria to be heavily colonized by bryozoans and algae might result from its high surface wettability, which could facilitate initial attachment of larvae and spores.

Fouling in the laboratory and algal characteristics 

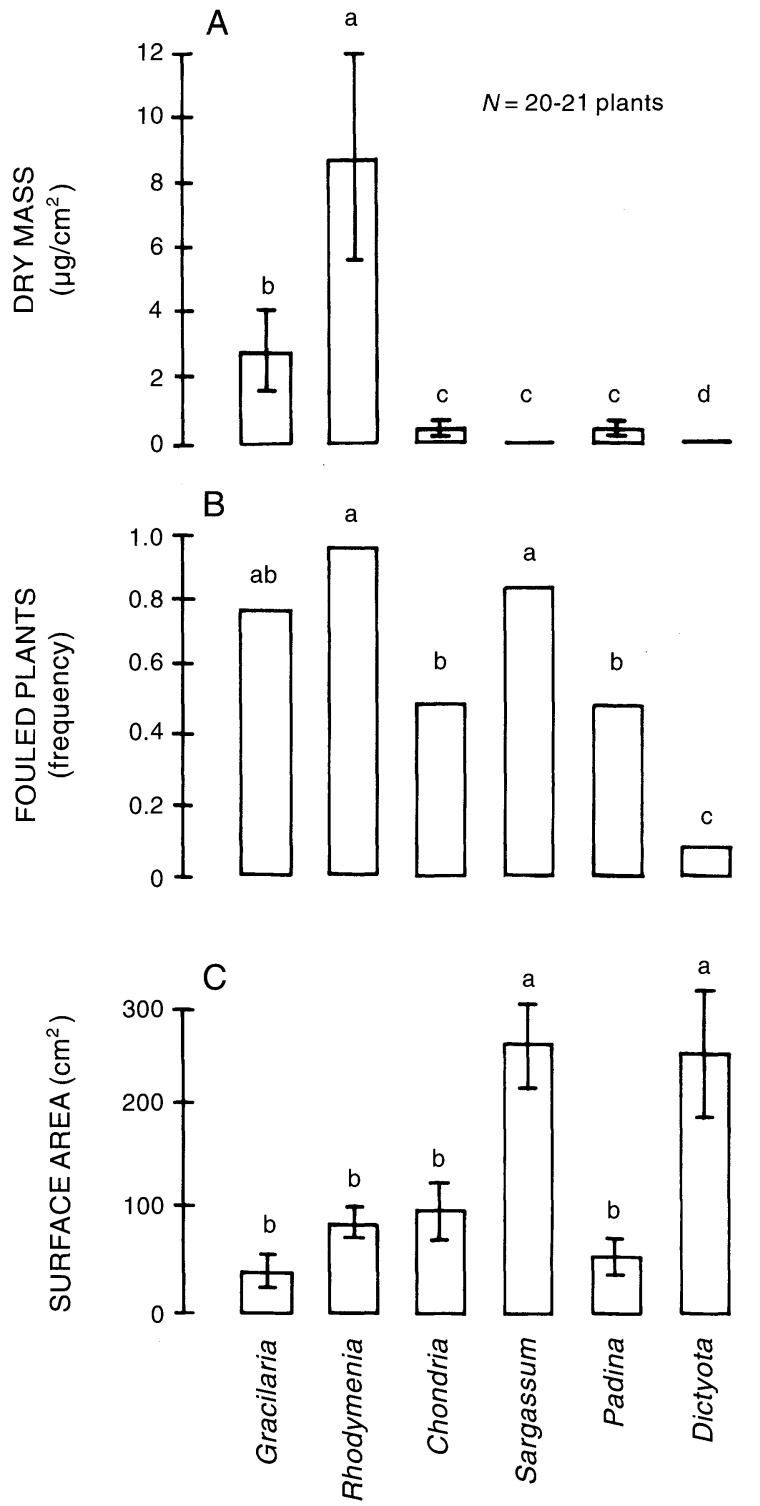

FIG. 1. (A) Dry mass of organisms per square centimetre of algal surface area (mean $\pm 1 \mathrm{SE}$ ) for six species of seaweeds collected from Radio Island Jetty. Analysis was by one-way ANOVA of ranks (see Methods). (B) The frequency with which plants of each species were fouled. Analysis was by a $G$ test with Sidak corrections for multiple comparisons. (C) The mean surface area per plant (i.e., area available for colonization) of the seaweeds analyzed in the above histograms. Analysis was by ANOVA followed by a Student-Newman-Keuls (SNK) test. In all histograms, letters above the bars denote significant groupings.

affecting fouling.-When newly released larvae of the bryozoan Bugula neritina were placed in bowls with seven common algal species, no larvae settled on Dictyota (Fig. 3). All other algal species experienced at least some settlement. Rhodymenia and Gracilaria were the most heavily fouled algae in the field (Fig. 1) and were the species onto which the greatest number

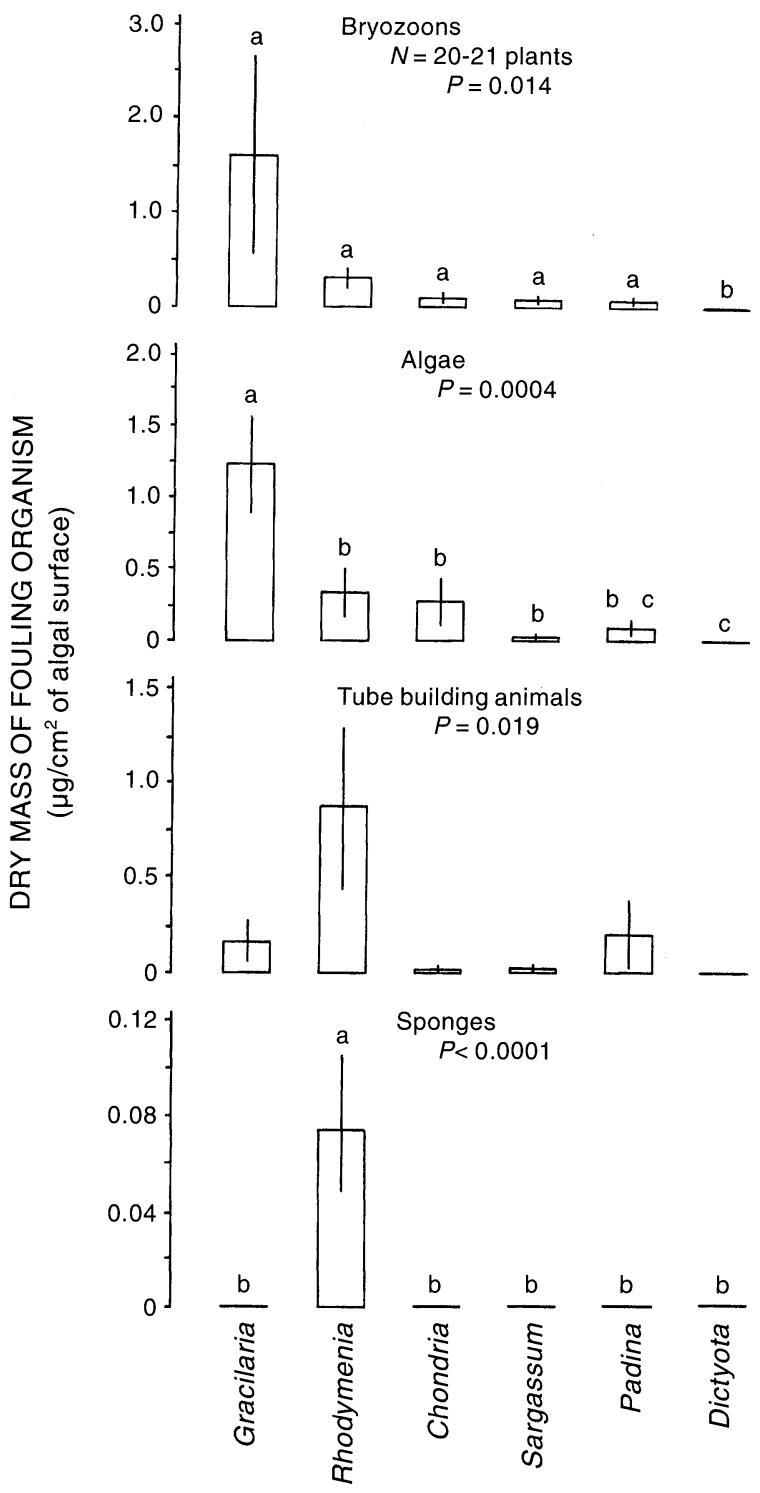

FIG. 2. Abundance of the four most common groups of fouling organisms found on the six seaweeds sampled. These four groups comprised $99 \%$ of the dry mass of all fouling organisms. $P$ values are from a one-way ANOVA of ranks. Other symbols are as in Fig. 1. Note that scales of the $y$-axes differ.

of Bugula larvae settled in these laboratory assays. Similarly, field collections showed Dictyota to be the least fouled alga, and it was avoided completely by larvae settling in the laboratory. The similarity of these patterns suggests that our laboratory experiments with Bugula settling behavior are generally congruent with patterns established for the broader fouling community under field conditions.

Proportional settlement of Bugula larvae was significantly higher than expected (i.e., $P \leq 0.0085$ to correct for multiple contrasts) on Gracilaria $(P=$ 0.002 ), and significantly lower than expected on Dic- 


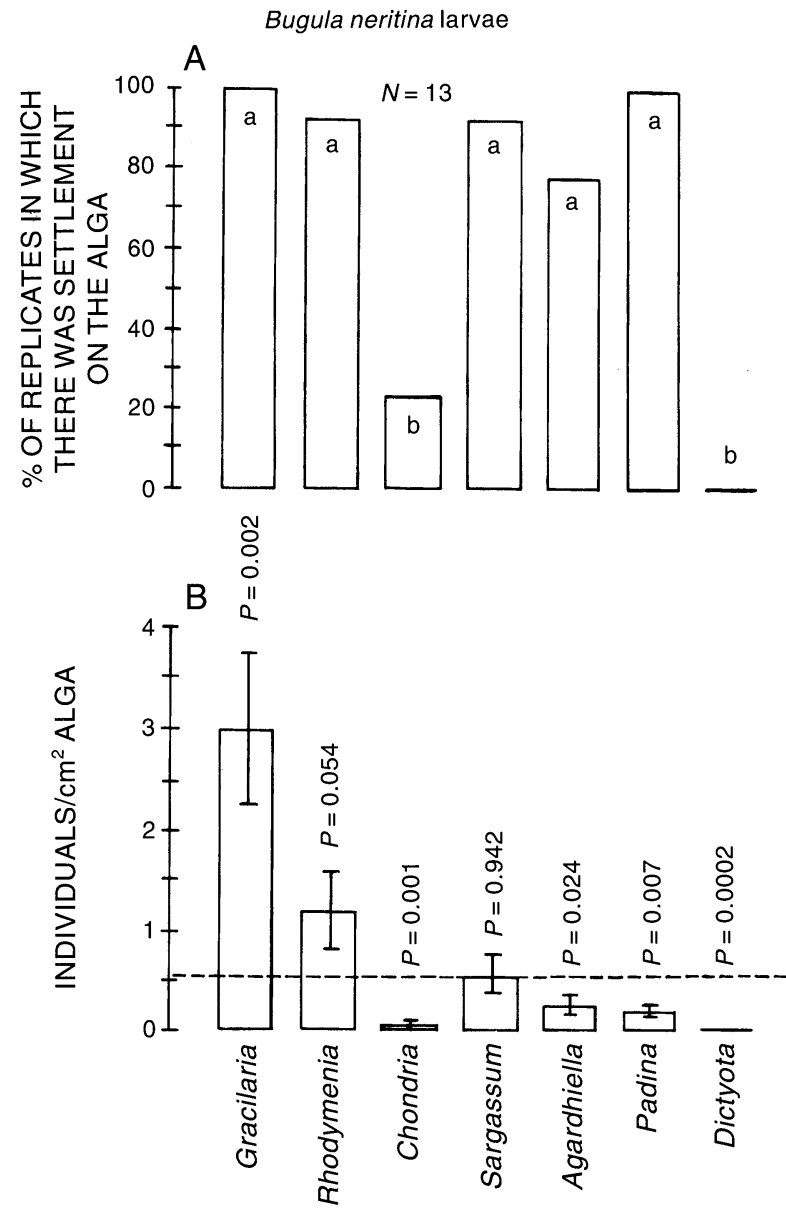

FIG. 3. (A) Percentage of replicates in which each algal species was colonized by larvae of the bryozoan Bugula neritina during laboratory assays. Analysis was by a $G$ test with Sidak corrections for multiple comparisons. (B) Density of larvae settling on each algal species. The dashed line indicates the predicted density if settlement had been random. $P$.values are by a paired $t$ test comparing observed and predicted densities for each species. Because there was no variance in settlement on Dictyota (all values were zero), we used a sign test for that species. To keep the experimentwise error rate $(\alpha)$ at 0.05 across the seven comparisons, an adjusted $\alpha$ of 0.0085 would be necessary.

tyota $(P=0.0002)$, Chondria $(\mathrm{P}=0.001)$, and Padina $(P=0.007$, Fig. 3). Because all algal species were available in each replicate (i.e., treatments were not independent), high settlement on one species could mandate lower than expected settlement on some others. These analyses are thus context dependent (i.e., could change with a change in which algal species are available). However, our $G$ test procedures (Fig. 3A) do not require independence of treatments and are, therefore, more rigorous than the above analyses, which we provide primarily as a description of differences in settlement densities rather than just frequencies of fouling. In our laboratory assays, no larvae attached to Dictyota in any of the 13 replicates, and settlement on Chondria occurred in only 3 of the 13 replicates. Both Dictyota and Chondria were colonized significantly less frequently than were any of the other algae ( $G$ test, $P<0.05$ ); all other algal species were colonized in 80 to $100 \%$ of the replicates.

Bugula larvae did not avoid Dictyota because compounds leaching into the water around the plant would negatively affect larval demography. When Bugula larvae were held in water collected from within Dictyota clumps at slack tide vs. water collected at least $1 \mathrm{~m}$ away from Dictyota, there was no difference in their survivorship, settlement, or development (Fig. 4). In both treatments, $\approx 85 \%$ of the Bugula larvae used in these assays developed two zooids within $24 \mathrm{~h}$, and a paired $t$ test indicated no difference in the number of individuals reaching this stage after $24 \mathrm{~h}(P=0.66, N$ $=$ 18, Fig. 4).

When Bugula larvae were placed in petri dishes with Dictyota and Gracilaria, there was no difference in the number of contacts that larvae made with each alga during a 2-min observation period (paired $t$ test, $P=$ $0.75, N=10$, Fig. 5). After $\approx 24 \mathrm{~h}, 97$ times more larvae had settled on Gracilaria than on Dictyota $(P$ $<0.0001, N=10$, paired $t$ test, Fig. 5). One larva had settled on Dictyota in one of the replicates; Gracilaria had been colonized in every replicate.

The demonstration that larvae are not affected by water from near Dictyota (Fig. 4), do not avoid contacting Dictyota relative to an alga favored for settlement (Fig. 5), but will not settle on Dictyota following contact (Fig. 5), suggests that whatever repels larvae is located on the surface of Dictyota but not released into the water. These observations suggested the presence of a deterrent lipophilic (i.e., not water soluble) compound located on the surface of Dictyota.

When extracts from swabs rubbed over the surface of Dictyota were coated onto settlement plates, Bugula

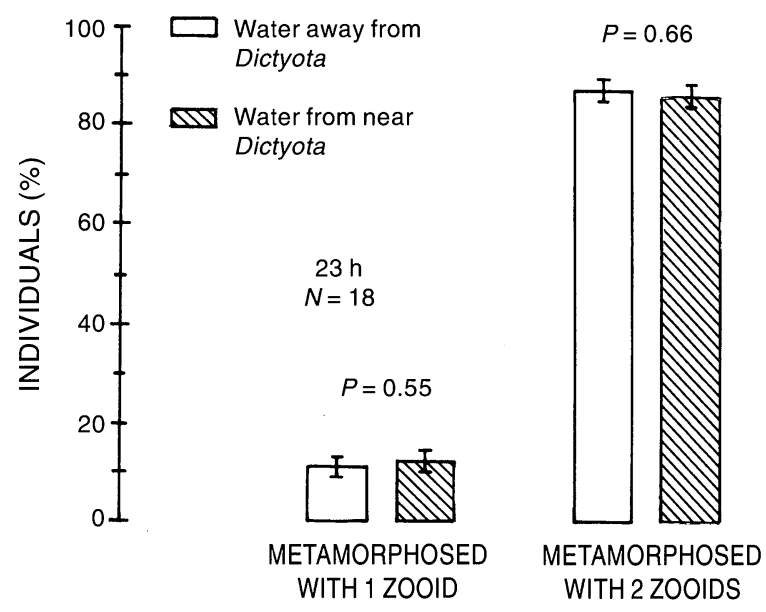

Fig. 4. Settlement and stage of development of Bugula neritina larvae held for $24 \mathrm{~h}$ in water collected from the center of Dictyota plants vs. $>1 \mathrm{~m}$ away from any Dictyota plant. $P$ values are from paired $t$ tests. 


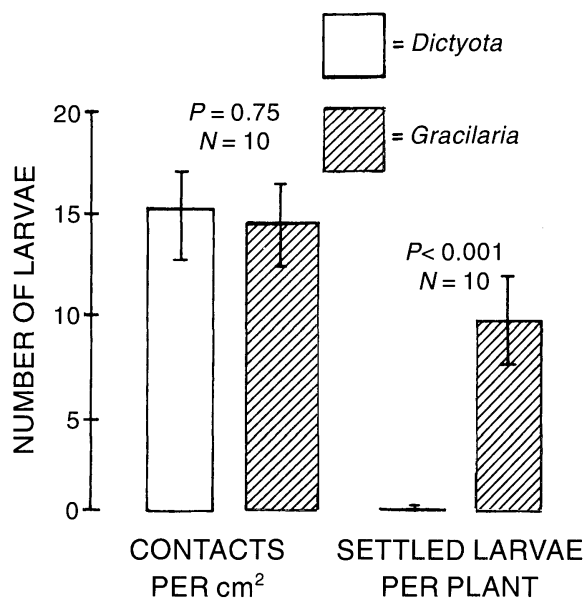

FIG. 5. Number of Bugula neritina larvae contacting Gracilaria (a preferred settlement site) vs. Dictyota (a low preference settlement site) during 2-min observation periods in the laboratory, and the number of larvae that had settled on each alga 24 h later. $P$ values are from paired $t$ tests.

settlement was reduced significantly relative to controls $(P<0.0001, N=22$, paired $t$ test, Fig. 6). Highperformance liquid chromatography of surface swabbings from Dictyota produced peaks with retention times that suggested the presence of the diterpene alcohols pachydictyol A and dictyol E, which are known to occur in Dictyota menstrualis (Hay et al. 1987a as D. dichotoma). Further analysis by mass spectrometry confirmed the peaks to be these compounds.

When the Dictyota diterpene pachydictyol A was coated onto our polystyrene settling dishes, these dishes were filled with seawater and allowed to sit for $1 \mathrm{~h}$, and then the seawater and the dish surface were extracted separately, we recovered $9 \pm 3 \%$ (mean \pm 1 $\mathrm{SE}$ ) of our compound from the dish surface and $0.1 \pm$ $0.1 \%$ from the seawater ( $N=9$ for both determinations). Given that polystyrene is an organic polymer, it seems reasonable to assume that the majority of our organic secondary metabolite migrated into this organic matrix and became difficult to extract. In contrast, when pachydictyol A (in ethanol) was added to the seawater in these dishes (rather than coated onto the dish surface) and allowed to stand for $1 \mathrm{~h}, 47 \pm$ $5 \%$ of the compound was recovered from the seawater while only $2 \pm 0.4 \%$ was recovered from the dish surface. Again, we assume that the missing 51\% may have been bound to the dish surface. Although pachydictyol A is a lipophilic compound; small quantities of compounds with solubility characteristics similar to those of pachydictyol A are known to occur in seawater (Kennish 1989).

These findings suggested that larvae placed in dishes coated with this secondary metabolite could avoid exposure to the metabolite by refusing to settle on the treated surface (as suggested by Figs. 5 and 6). In contrast, larvae placed in dishes where compounds were dispersed in the water would be unable to behaviorally avoid prolonged exposure to the compounds. Thus, the physiological (as opposed to behavioral) effects of exposure to the compounds can be measured by placing both larvae and compounds in the water.

When Bugula larvae were placed in water containing the Dictyota secondary metabolites, dictyol E killed larvae before they settled but had no demonstrable effect on the growth or survivorship of juveniles (we thus graphed only the effects on larval survivorship, Fig. 7); in contrast, pachydictyol A had no effect on larval survivorship but did affect development, growth, and survival of settled juveniles (we thus graphed only these effects for pachydictyol A, Fig. 8). Dictyol E was toxic to Bugula larvae in the 10 and $5 \mu \mathrm{g} / \mathrm{mL}$ treatments (Fig. 7). At $10 \mu \mathrm{g} / \mathrm{mL}, 95 \%$ of the larvae were dead within $24 \mathrm{~h}$; there was no significant increase in mortality over the next $48 \mathrm{~h}$. At $5 \mu \mathrm{g} / \mathrm{mL}, 75 \%$ of the larvae died within $24 \mathrm{~h}$, and $85 \%$ were dead by the end of the experiment $(72 \mathrm{~h})$. At concentrations below $5 \mu \mathrm{g} / \mathrm{mL}$, there were no significant effects on larval mortality or settlement and development relative to controls. Effects of dictyol $\mathrm{E}$ at 5 and $10 \mu \mathrm{g} / \mathrm{mL}$ on settlement and development (as opposed to mortality) of larvae and juveniles could not be reliably assessed because so few larvae survived to settle. In the $10 \mu \mathrm{g} / \mathrm{mL}$ treatment, survival occurred in only two of our 13 replicates; each of these had a single surviving juvenile after $72 \mathrm{~h}$. These juveniles were both at the single zooid stage while $98 \%$ of the juveniles in the controls had progressed to the two-zooid stage. After $72 \mathrm{~h}$ in the 5 $\mu \mathrm{g} / \mathrm{mL}$ treatment, five replicates had no survivors, six had 1-3 survivors, one had 5 , and one had 8 survivors. Of the surviving juveniles, $45 \%$ (9 of 20 ) were at the one-zooid stage while only $2 \%$ of the controls had not progressed beyond this point.

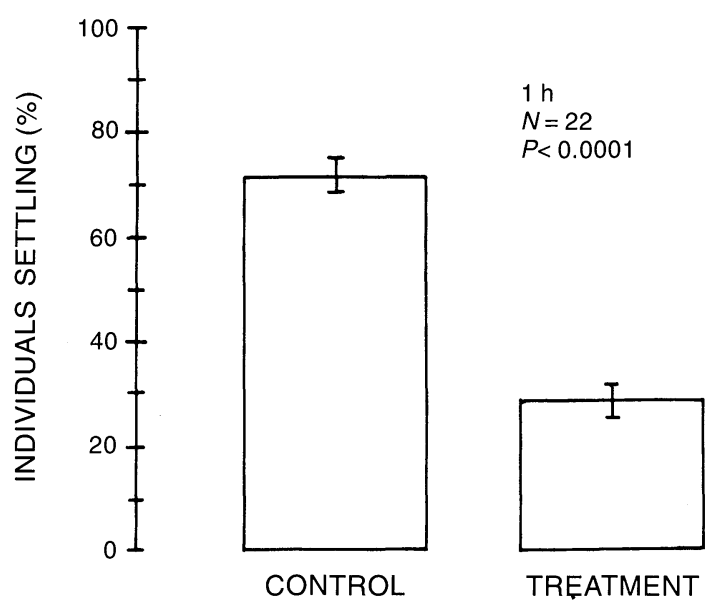

FIG. 6. Percentage of Bugula neritina larvae settling after $1 \mathrm{~h}$ on the portion of a polystyrene surface treated with the lipid-soluble extract from surface rubbings of Dictyota vs. the control side of this same surface. The $P$ value is from a paired $t$ test. 


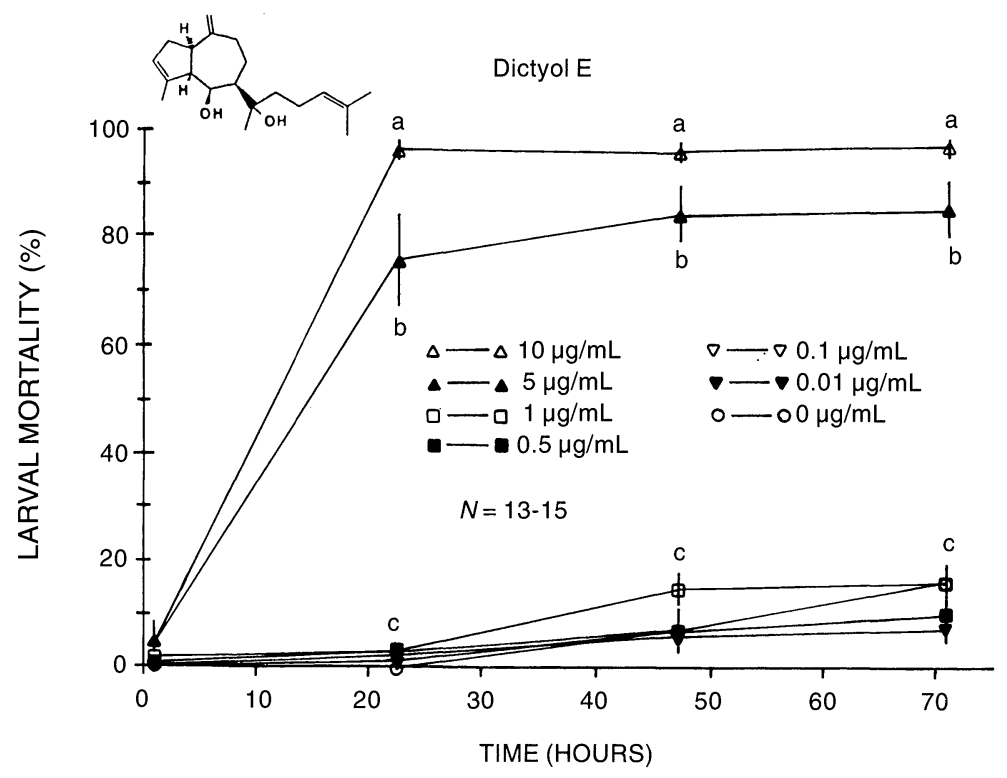

FIG. 7. Mortality of Bugula neritina larvae held in water containing various concentrations of the Dictyota secondary metabolite dictyol E. Letters at each time interval show significant groupings at that time interval, as indicated by ANOVA and SNK analyses.

In contrast to the toxic effects of dictyol $\mathrm{E}$, pachydictyol A had no effect on the survivorship of Bugula larvae $(P=0.80)$, but did affect the development and survivorship of newly settled juveniles. At higher concentrations of pachydictyol A, juveniles were deformed and their development was retarded (Fig. 8). Most individuals settled and developed one zooid within $19 \mathrm{~h}$; however, a significant $(P<0.0001$, ANOVA/SNK) 27$34 \%$ of the individuals in the 1,5 , and $10 \mu \mathrm{g} / \mathrm{mL}$ treatments were metamorphosed but deformed relative to the controls (Fig. 8). As the experiment progressed, metamorphosed individuals in the high concentration treatments began to die; 12 and $14 \%$ of the juveniles in the 5 and $10 \mu \mathrm{g} / \mathrm{mL}$ treatments, respectively, were dead at $42 \mathrm{~h}$, and this increased to a significant 24 and $26 \%(P<0.0001)$ after $67 \mathrm{~h}$ (Fig. 8). In addition, significantly fewer survivors developed to the two-zooid stage in the 1,5 , and $10 \mu \mathrm{g} / \mathrm{mL}$ treatments (Fig. 8). Eighty-four to $91 \%$ of the individuals in the $0,0.01$, 0.1 , and $0.5 \mu \mathrm{g} / \mathrm{mL}$ treatments developed to the twozooid stage within $67 \mathrm{~h}$. At concentrations of 1, 5, and $10 \mu \mathrm{g} / \mathrm{mL}$, proportions of larvae developing to the twozooid stage by $67 \mathrm{~h}$ were: $62 \%, 42 \%$ and $40 \%$, respectively. The percentages of individuals with twozooids in the three lower concentration treatments and the control were grouped together by ANOVA/SNK, and were significantly different from the $1 \mu \mathrm{g} / \mathrm{mL}$ treatment, which was in turn significantly different from the 5 and $10 \mu \mathrm{g} / \mathrm{mL}$ treatments (Fig. 8).

Although surface wettability can influence larval settlement, it does not appear to explain why Bugula larvae avoid settling on Dictyota. Although both advancing and receding contact angles differed significantly among algal species (ANOVA, $P<0.0001$ for both analyses), subsequent SNK tests at $\alpha=.05$ showed that Dictyota fell in the middle of the other algal species. Its wettability differed significantly only from the receding contact angle of Gracilaria (Fig. 9).

Regression of Bugula settlement densities on algal wettabilities were significant for advancing and receding angles $\left(r^{2}=0.57, P=0.05\right.$ and $r^{2}=0.65, P=$ 0.03 , respectively). However, the high settlement densities on, and a high surface wettability of, Gracilaria accounted for almost all of this relationship. When Gracilaria was removed from the analysis, the regressions were no longer significant $\left(r^{2}=0.29, P=0.27\right.$ and $r^{2}=0.19, P=0.39$ for advancing and receding angles, respectively).

In summary, the affinity of Bugula larvae for Gracilaria may result, in part, from the wettability of its surface. However, the wettability of Dictyota is intermediate to the other algae used in our assays, does not differ significantly from any other alga in advancing angle, and differs significantly only from Gracilaria when considering receding angle (Fig. 9). Nothing in these data suggests that larvae avoid Dictyota due to its surface wettability.

\section{DisCUSSION}

Seaweeds fouled by either plants or animals can experience reduced rates of photosynthesis, growth, and reproduction due to increased shading, competition for nutrients, and interference with reproductive processes (Orth and van Montfrans 1984, Brawley 1992, Williams and Seed 1992). Additionally, they may lose biomass that would not normally have been lost if con- 

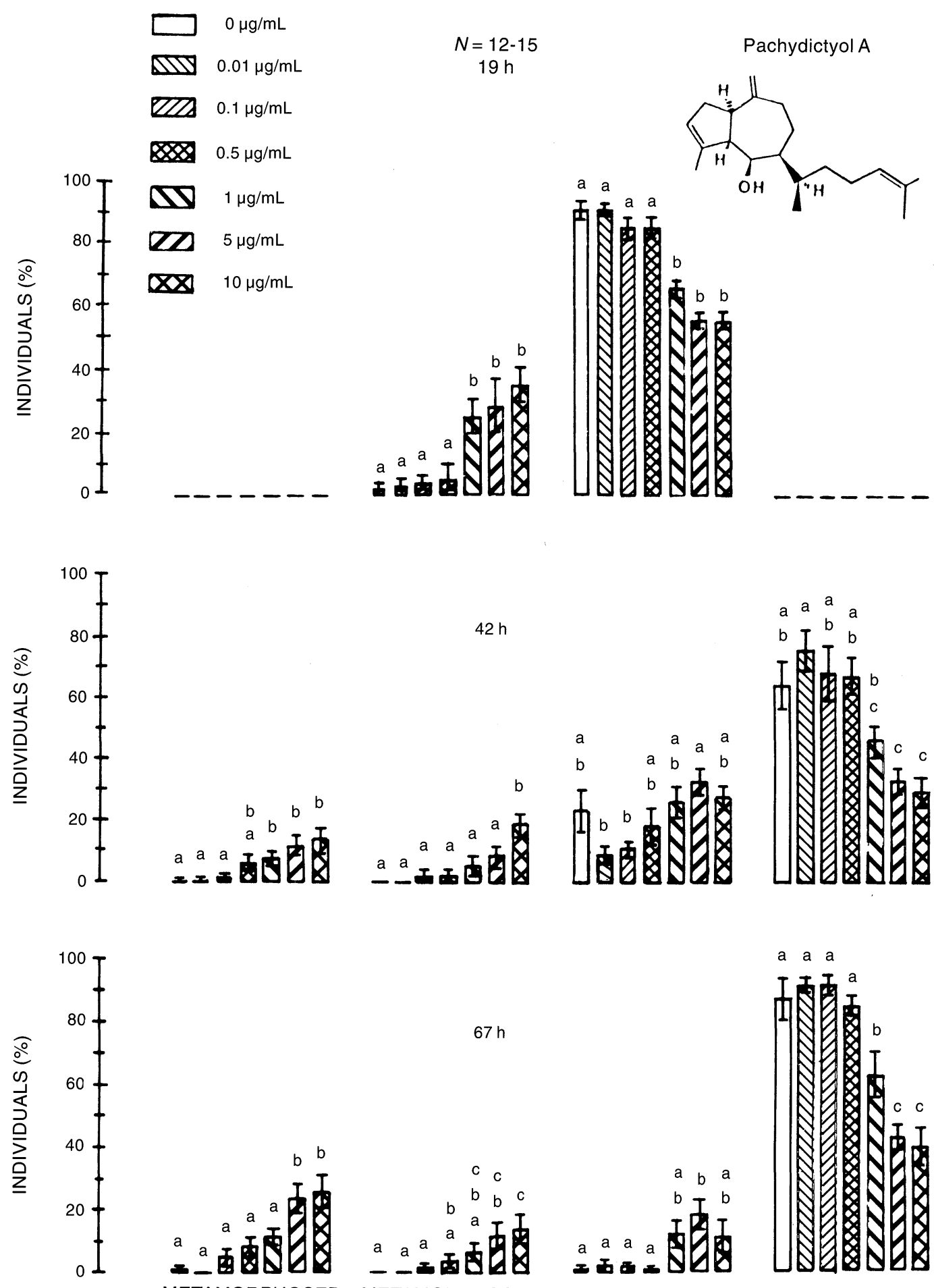

$67 \mathrm{~h}$

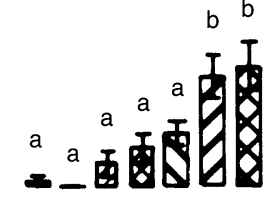

METAMORPHOSED AND DIED

(67h
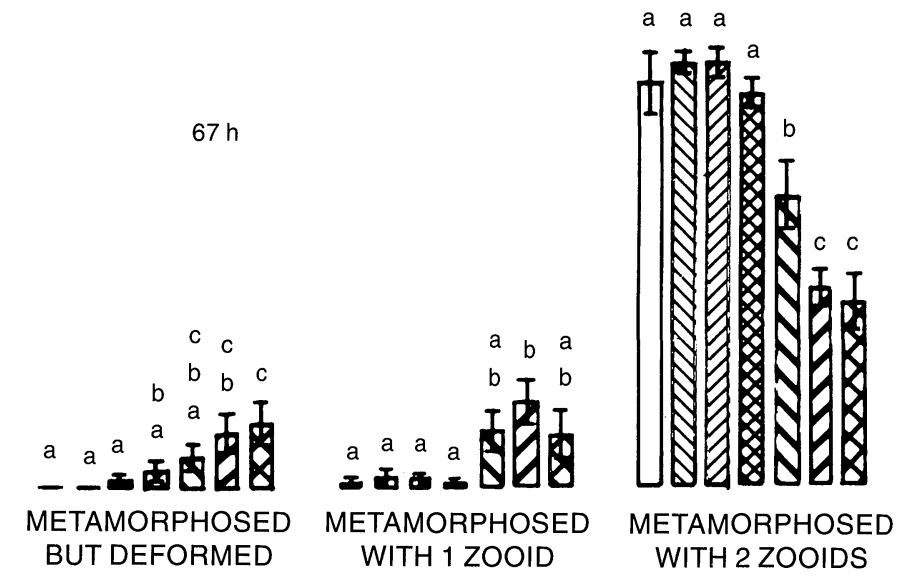

FIG. 8. Fate and stage of development of settled larvae of Bugula neritina after $19 \mathrm{~h}$ (top), $42 \mathrm{~h}$ (middle), and $67 \mathrm{~h}$ (bottom) in water containing various concentrations of the Dictyota secondary metabolite pachydictyol A. Letters above the bars in each histogram show significant groupings by ANOVA and SNK analyses. 
A. Advancing Angle
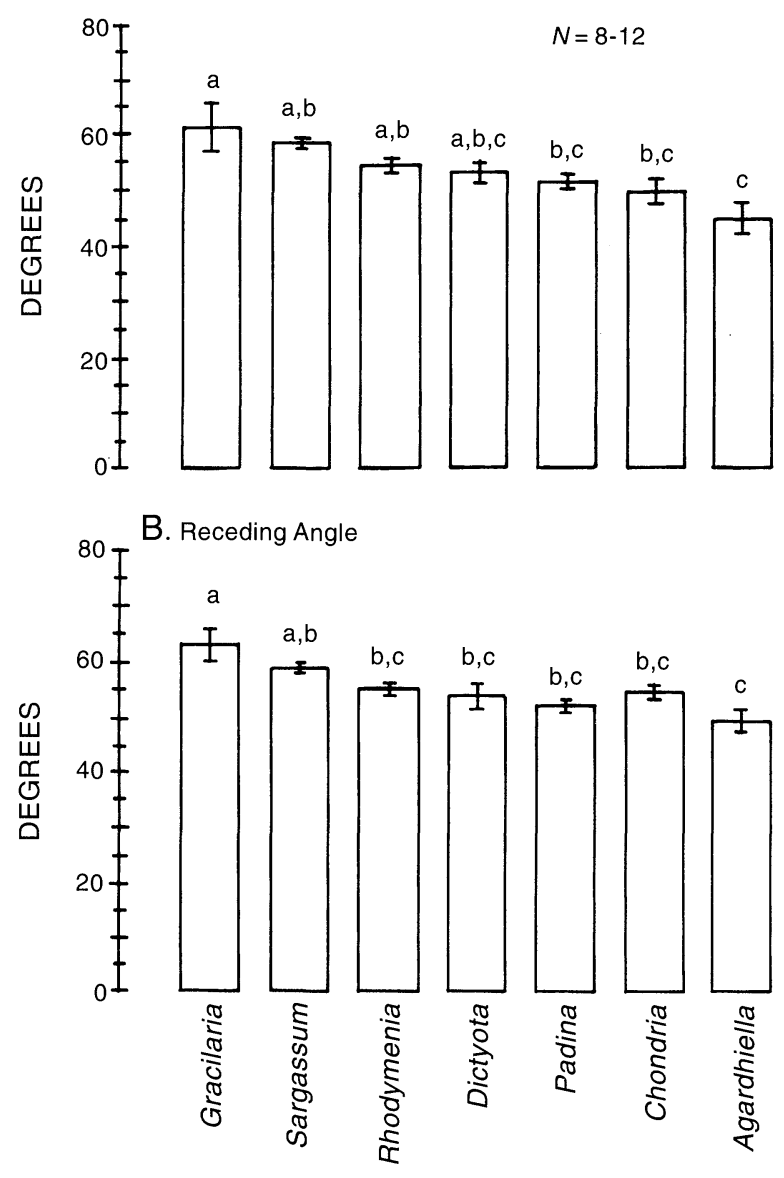

FIG. 9. Surface wettability (expressed in degrees, see Methods for an explanation) of advancing (A) and receding (B) angles for the seven seaweeds used in our larval settling assays. Analyses were by ANOVA and SNK.

sumers feed on common fouling organisms and take portions of the seaweed in the process (Bernstein and Jung 1979). Mortality also can increase because the surface area of fouling organisms increases drag and causes plants to be dislodged by waves (see Brawley 1992, Williams and Seed 1992). All of these processes could select for seaweed characteristics that minimize colonization by fouling organisms.

Experimental investigations of how seaweeds reduce fouling are rare. Various brown seaweeds and red crustose algae periodically shed layers of surficial cells, thus eliminating some foulers (Moss 1982, Masaki et al. 1984, Johnson and Mann 1986); however, Keats et al. (1993) questioned the general effectiveness of this process as a way of reducing overgrowth. Fouling can also be diminished by co-occurring consumers that feed on fouling organisms but cause minimal damage to the host alga (Brawley and Adey 1981, Steneck 1982, Duffy 1990 , Brawley 1992).

These antifouling mechanisms are apparently not used extensively by Dictyota. Sloughing of surficial cells does not appear to be an option for Dictyota because it has only one layer of surface cells overlying a single layer of large, nonpigmented medullary cells. Additionally, although some amphipods are known to selectively associate with Dictyota, these amphipods eat Dictyota as readily as some of its epiphytes (Hay et al. 1987a, 1990, Duffy and Hay 1991, 1994), suggesting that they might impose a high cost for their cleaning services. Different species of amphipods or other mesograzers could, however, be acting primarily as epiphyte grazers (Brawley and Adey 1981, Duffy 1990, Brawley 1992).

Sieburth and Conover (1965) noted that seaweedderived phenolics placed in seawater inhibited the settlement of a variety of fouling organisms and suggested that the inverse relationship between the fouled and phenolic-poor lower leaves of Sargassum and the clean and phenolic-rich upper leaves is causative. However, this contrast is confounded because lower leaves represent old settlement surfaces low in the water column and upper leaves represent new ones high in the water column. To our knowledge, no previous investigation has rigorously documented that larvae avoid settling on a particular alga and that this avoidance is chemically mediated.

In contrast, several investigations have documented that settlement of benthic invertebrates may be stimulated by chemical signals on the surface of particular algae (see Morse 1992 and Pawlik 1992 for reviews), and numerous investigations of benthic marine invertebrates have suggested that they use secondary metabolites as defenses against fouling (see reviews by Davis et al. 1989 and Wahl 1989, but also the cautions of Pawlik 1992). However, for most studies, it is unclear if the methods, concentrations, and organisms used in the bioassays were ecologically realistic. In most assays, compounds that are apparently contained in organisms are extracted and tested on surfaces without first documenting that settling larvae would ever contact these compounds if they were colonizing undamaged hosts (see review by Pawlik 1992). These uncertainties involving where compounds occur in the host, how they are deployed, and what constitutes an ecologically realistic assay concentration are critical problems without clear solutions, given present technologies. These uncertainties have prevented more rapid assessment of the importance of secondary metabolites as antifouling agents.

In this study, we found that plants of Dictyota menstrualis at our field site were less frequently and less heavily fouled than any of the five other seaweed species that were evaluated (Fig. 1). In laboratory assays, larvae of the bryozoan Bugula neritina, an invertebrate that commonly fouls seaweeds and other invertebrates, refused to settle on Dictyota (Fig. 3) even though they contacted the surface of Dictyota as often as they contacted the surface of a preferred host alga (Fig. 5). 
Rejection of Dictyota as a settlement site could not be explained by surface wettability (Fig. 9) or by chemicals leached into water surrounding the plant (Fig. 4). Rejection occurred only after direct contact with the alga's surface. The crude lipid-soluble extract from surface rubbings of Dictyota inhibited larval settlement when placed on other surfaces (Fig. 6) and contained the diterpene alcohols pachydictyol $\mathrm{A}$ and dictyol $\mathrm{E}$.

It is presently impossible to determine the concentration of these compounds that a larva would experience when settling on the surface of Dictyota (see the list of problems given in the Methods section). However, when larvae could not behaviorally avoid exposure to the compounds (i.e., the compounds were placed in their water), the compounds caused larval mortality (Fig. 7), abnormal development, and reduced rates of growth (Fig. 8) in treatments containing $1-10 \mu \mathrm{g} / \mathrm{mL}$ of the Dictyota secondary metabolites. Because only $47 \%$ of these treatment concentrations could actually be demonstrated to be in the water after $1 \mathrm{~h}$, concentrations experienced by the larvae could be half, or less, of the reported treatment concentrations.

Similar experiments with larvae of the bryozoan Amathia convoluta and the hydroid Eudendrium carneum, and with additional diterpenes from this and another species of Dictyota (D. ciliolata), show very similar patterns (T. M. Schmitt et al., unpublished manuscript), suggesting that these Dictyota secondary metabolites are broadly active against a wide range of fouling organisms. This is also suggested by data from our field collections (Figs. 1 and 2) showing that all the common fouling organisms at our site (bryozoans, algae, tubebuilding animals, and sponges) were absent or rare on Dictyota compared with the other seaweeds.

The same compounds that we show harm the larvae of fouling organisms have been shown to function as defenses against common marine herbivores such as fishes, urchins, and amphipods (Hay and Fenical 1992). Pachydictyol A significantly reduces grazing by: (1) reef fishes in the Caribbean (Hay et al. 1987b) and tropical Pacific (Wylie and Paul 1988, Hay 1991a), (2) omnivorous fishes and an urchin in the temperate Atlantic (Hay et al. 1987a, 1988), and (3) by some, but not all, of the mesograzers (e.g., amphipods and polychaetes) against which the compound has been tested (Hay et al. 1987a, 1988, 1990, Duffy and Hay 1994). Dictyol $E$ shows a similar activity against numerous herbivores but appears to be ineffective as a deterrent to tropical fishes (see the summary tables in Hay 1991 $a$, Hay and Fenical 1992). Additionally; tests with other compounds in the dictyol family of metabolites show that several of these function as defenses against herbivores (summarized in Hay 1991 $a$ and Hay and Fenical 1992) and interfere with survival, development, or growth of larvae and juveniles of common fouling organisms (T. M. Schmitt et al., unpublished manuscript).

The dictyols are produced by numerous brown algae in the order Dictyotales, including species in the genera
Dictyota, Pachydictyon, Glossophora, and Dilophus (Faulkner 1991 and his earlier reviews referenced in that paper). Seaweeds producing these compounds are unusually successful species in that they are often very abundant in a wide variety of divergent habitats (e.g., grassbeds, reefs, reef flats, mud flats, and as epiphytes on animals, other algae, and mangrove roots) in both temperate and tropical latitudes. Several of the species in these genera are relatively resistant to herbivores (Hay 1981a, 1984, Littler et al. 1983, Paul and Hay 1986), yet are also relatively good competitors in situations where herbivory is minimized (Hay and Taylor 1985, Lewis 1986, Morrison 1988). This contrasts with an apparent pattern of seaweeds that are well defended against herbivores being poor competitors in situations where herbivory is minimal (Hay 1981b, 1985, Lubchenco and Gaines 1981, Lewis 1986, Morrison 1988, Estes and Steinberg 1988). Dictyota may circumvent the competitive costs of herbivore deterrence because the same traits that confer resistance to herbivores also provide competitive advantages via allelopathic properties.

There has been considerable debate over the importance of coevolution and gene-for-gene reciprocal interactions in shaping the evolution of plant-herbivore interactions (Ehrlich and Raven 1964, Fox 1981, Futuyma and Slatkin 1983, Bernays and Graham 1988, Spencer 1988, Thompson and Burdon 1992, Vermeij 1992). Our finding that individual compounds can be advantageous as both herbivore deterrents and allelopathic agents complicates the potential for significant coevolution mediated via these chemical defenses, especially given the common assumption that herbivore deterrent characteristics entail competitive costs, not benefits (see Lubchenco and Gaines 1981, Hay 1984). Although the tight coupling of plant genes for defense with pathogen genes for resistance has been demonstrated for several crop plants and their specialized fungal pathogens, it is not clear that similar interactions occur between plants and herbivores (see the review by Thompson and Burdon 1992). In some herbivorous insects, oviposition preference is controlled by different genes than those that control larval performance (Thompson et al. 1990). This may make the genetics of insect attack more complex than the genetics of attack by pathogens, and the life history differences between insects and pathogens may make gene-for-gene interactions much more common for microbial pathogens than for insects (Thompson and Burdon 1992). Additionally, in natural field populations, there appears to be no clear pattern of reciprocal responses between hosts and pathogens at the spatial scale of the individual host and pathogen demes; natural populations appear more strongly influenced by genetic drift, extinction, and gene flow that occur at random among demes within the same epidemiological region (Thompson and Burdon 1992).

For Dictyota menstrualis in the temperate Atlantic, 
pachydictyol A and dictyol E serve as feeding deterrents against a wide range of generalist herbivores (Hay et al. 1987a, 1988, Duffy and Hay 1994) and also damage the larvae of several species of fouling organisms (Figs. 1-3, 5-8; T. M. Schmitt et al., unpublished manuscript). The relative selection imposed by herbivores vs. overgrowth by competitors is not known for seaweeds in this region; however, both herbivores and competitors have been demonstrated to have large effects on seaweed populations in other habitats (Dayton 1975, Lubchenco 1980, Lubchenco and Gaines 1981, Hay 1985, 1991a, Lewis 1986, Morrison 1988). The multiple functions of these compounds against numerous foulers and herbivores should constrain the plant from dramatically altering its chemical defenses in response to the evolution of resistance by any individual herbivore or fouling species. If secondary plant metabolites commonly serve multiple functions that are ecologically important, then coevolution between plants and herbivores may be less common than is generally thought.

Several recent studies suggest that this may be the case. In marine communities, the relationships between seaweeds and herbivores that seem to be most coevolved appear, from the paleontological record, to result from fortuitous preadaptations (or exaptations, see Gould and Vrba 1982) rather than from a long history of reciprocal adaptation (Hughes and Gliddon 1991, Steneck 1992, Hay et al. 1994). As an example, initial investigations of the encrusting coralline alga Clathromorphum circumscriptum and its relatively specialized limpet grazer Tectura testudinalis (previously Acmaea testudinalis) found a number of apparently coevolved adaptations that were of mutual benefit to both organisms (Steneck 1982). Evidence of this coevolved relationship included: (a) abundances of the alga and limpet were positively correlated, (b) the alga produced a unique protective covering of tissue over its regions of active growth, (c) the limpet's radula was apparently adapted to eat this thickened tissue in a way that did minimal damage to the host alga or its sunken reproductive structures, (d) limpet grazing prevented the algal host from being overgrown by potentially lethal epiphytic algae, (e) the limpet was less susceptible to its predators when clamped down on the hard smooth surface of the alga (Steneck 1990), and (f) over a wide range of depths, the rate of cell removal by limpets was matched by algal production.

Fortunately, in addition to this very suggestive ecological information, Steneck (1992) was also able to evaluate the paleontological record involving coralline algae and herbivores. Because coralline algae are calcified, they have left an excellent fossil record that includes a history of their anatomical characteristics, which have been interpreted as evolutionary responses to herbivores, as well as grazing scars on their surfaces that can be identified as being produced by limpets, urchins, fishes, etc. (Steneck 1983, 1986). Thus, the fossil record for coralline algae and their associated herbivores is apparently the most complete record for any plant-herbivore association, either terrestrial or marine (Steneck 1992). This record shows that virtually all of the coralline's major morphological characteristics that had been interpreted as adaptations to herbivores were present 100 million to several hundred million years before the evolution of marine herbivores that could feed on corallines (Steneck 1992).

Recent analysis of 12 specialist molluscs and their temperate seaweed hosts also suggests that these associations are more opportunistic than coevolved (Vermeij 1992). In 50\% of the cases studied, Vermeij found that the associations were recent (no earlier than the Pliocene) and resulted following invasion of the plant or the herbivore from geographical regions other than the one in which the association was forged. In contrast to the widely held view that associations between specialized herbivores and host plants evolve due to reciprocal adaptations over a long period of time, Vermeij's study suggests that a large proportion of these relationships may be opportunistic and arise rapidly with little, if any, history of reciprocal evolution.

In marine communities, it appears that some seaweeds possess chemical defenses that protect them against the cumulative effects of the larger, generalist herbivores (fishes, urchins, and gastropods) that commonly consume significant quantities of seaweeds and often drive some species to local extinction (Hay 1991a, Hay and Steinberg 1992). These well defended seaweeds then become potential safe sites where small, less-mobile herbivores that live on the plants they consume can minimize their contact with fish predators if they are resistant to the seaweed's defenses (Hay $1991 b$, Hay and Steinberg 1992). Although these small mesograzers can, at times, significantly affect seaweed communities and populations (Duffy 1990, Duffy and Hay 1991, Brawley 1992), the selective pressure they impose on plant populations usually appears trivial compared with the pressure imposed by the bigger, generalist herbivores (Hay 1991a, Hay and Steinberg 1992). This information, coupled with what we present here, suggests: (1) that plants may possess chemical defenses against the broad range of generalist herbivores and fouling organisms that are attacking them, (2) that small mesograzers may evolve resistance to these defensive traits because living on chemically defended seaweeds dramatically reduces their susceptibility to predation (Hay 1991b, Hay and Steinberg 1992), and (3) that there is little evidence to support the notion that any of these traits or interactions occur due to a history of coevolution. Small herbivores may be adapting to seaweed characteristics, but it is unclear that seaweeds are adapting in response to feeding by these small herbivores. Despite the long history of considering plant-insect interactions as coevolved, the importance of coevolution in shaping interactions between terrestrial plants and their insect herbivores is 
also open to question (Bernays and Graham 1988, Futuyma and Morano 1988, Spencer 1988, Thompson and Burdon 1992).

Given the multiple ecological functions that are played by the Dictyotalean metabolites studied here and investigated by T. M. Schmitt et al. (unpublished manuscript), it seems unlikely that these would have evolved in response to herbivory alone, much less in response to any particular herbivore.

\section{ACKNOWLEDGMENTS}

This investigation was supported by NSF grants OCE 89 11872 and 92-02847 to M. E. Hay and OCE 89-15304 to N. Lindquist. Dan Rittschof provided equipment and advice regarding measurement of contact angles. W. Fenical identified our compounds. Megan Dethier, James Estes, Joseph Pawlik, Peter Steinberg, Robert Steneck, and Nancy Targett provided comments that improved the manuscript.

\section{Literature Cited}

Baier, R. E. 1970. Surface properties influencing biological adhesion. Pages 15-48 in R. S. Manley, editor. Adhesion in biological systems. Academic Press, New York, New York, USA.

Bernays, E. A., G. C. Driver, and M. Bilgener. 1989. Herbivores and plant tannins. Advances in Ecological Research 19:263-302.

Bernays, E. A., and M. Graham. 1988. On the evolution of host specificity in phytophagous arthropods. Ecology 69: 886-892.

Bernstein, B. B., and N. Jung. 1979. Selective pressures and coevolution in a kelp canopy community in southern California. Ecological Monographs 49:335-355.

Brawley, S. H. 1992. Mesoherbivores. Pages 235-263 in D. M. John, S. J. Hawkins, and J. H. Price, editors. Plantanimal interactions in the marine benthos. Systematics Association Special Volume 46. Clarendon, Oxford, England.

Brawley, S. H., and W. H. Adey. 1981. The effect of micrograzers on algal community structure in a coral reef microcosm. Marine Biology 61:167-177.

Coley, P. D., and T. M. Aide. 1990. A comparison of herbivory and plant defenses in temperate and tropical broadleaved forests. Pages 25-49 in P. W. Price, T. M. Lewinsohn, G. E. Fernandes, and W. W. Benson, editors. Plant-animal interactions: evolutionary ecology in tropical and temperate regions. John Wiley, New York, New York, USA.

Coley, P. D., J. P. Bryant, and F. S. Chapin, III. 1985. Resource availability and plant antiherbivore defense. Science 230:895-899.

Crawley, M. J. 1989. The relative importance of vertebrate and invertebrate herbivores in plant population dynamics. Pages 45-71 in E. A. Bernays, editor. Insect-plant interactions. Volume I. CRC Press, Boca Raton, Florida, USA.

Davis, A. R., N. M. Targett, O. J. McConnell, and C. M. Young. 1989. Epibiosis of marine algae and benthic invertebrates: natural products chemistry and other mechanisms inhibiting settlement and overgrowth. Bioorganic Marine Chemistry 3:85-114.

Dayton, P. K. 1975. Experimental evaluation of ecological dominance in a rocky intertidal algal community. Ecological Monographs 45:137-159.

Denno, R. F., and M. S. McClure. 1983. Variable plants and herbivores in natural and managed systems. Academic Press, New York, New York, USA.

Duffy, J. E. 1990. Amphipods on seaweeds: partners or pests? Oecologia 83:267-276.

Duffy, J. E., and M. E. Hay. 1991. Food and shelter as determinants of food choice by an herbivorous marine amphipod. Ecology 72:1286-1298.
Duffy, J. E., and M. E. Hay. 1994. Herbivore resistance to seaweed chemical defense: the roles of mobility and predation risk. Ecology 75:1291-1306.

Ehrlich, P. R., and P. H. Raven. 1964. Butterflies and plants: a study in coevolution. Evolution 18:586-608.

Estes, J. A., and P. D. Steinberg. 1988. Predation, herbivory, and kelp evolution. Paleobiology 14:19-36.

Faulkner, D. J. 1991. Marine natural products. Natural Products Reports 1:251-280.

Fox, L. R. 1981. Defense and dynamics in plant-herbivore interactions. American Zoologist 21:853-864.

Futuyma, D. J. 1983. Evolutionary interactions among herbivorous insects and plants. Pages 207-231 in D. J. Futuyma and M. Slatkin, editors. Coevolution. Sinauer, Sunderland, Massachusetts, USA.

Futuyma, D. J., and S. S. McCafferty. 1990. Phylogeny and the evolution of host associations in the leaf beetle genus Ophraella (Coleoptera, Chrysomelidae). Evolution 44: 1885-1913.

Futuyma, D. J., and G. Morano. 1988. The evolution of ecological specialization. Annual Review of Ecology and Systematics 19:207-233.

Futuyma, D. J., and M. Slatkin. 1983. Coevolution. Sinauer, Sunderland, Massachusetts, USA.

Gerhart, D. J., D. Rittschof, I. R. Hooper, K. Eisenman, A. E. Meyer, R. E. Bayer, and C. Young. 1992. Rapid and inexpensive quantification of the combined polar components of surface wettability: application to biofouling. Biofouling 5:251-259.

Gould, S. J., and R. C. Lewontin. 1979. The spandrels of San Marco and the panglossian paradigm: a critique of the adaptionist programme. Proceedings of the Royal Society, Series B 205:581-598.

Gould, S. J., and E. S. Vrba. 1982. Exaptation-a missing term in the science of form. Paleobiology 8:4-15.

Hay, M. E. 1981a. Spatial patterns of grazing intensity on a Caribbean barrier reef: herbivory and algal distribution. Aquatic Botany 11:97-109.

- 1981b. Herbivory, algal distribution, and the maintenance of between-habitat diversity on a tropical fringing reef. American Naturalist 118:520-540.

. 1984. Predictable spatial escapes from herbivory: how do these affect the evolution of herbivore resistance in tropical marine communities? Oecologia 64:396-407.

. 1985. Spatial patterns of herbivore impact and their importance in maintaining algal species richness. Proceedings of the Fifth International Coral Reef Congress 4:2934.

1991a. Fish-seaweed interactions on coral reefs: effects of herbivorous fishes and adaptations of their prey. Pages 96-119 in P. F. Sale, editor. The ecology of fishes on coral reefs. Academic Press, San Diego, California, USA.

- $1991 \mathrm{~b}$. Marine-terrestrial contrasts in the ecology of plant chemical defenses against herbivores. Trends in Ecology and Evolution 6:362-365.

Hay, M. E., J. E. Duffy, and W. Fenical. 1990. Host-plant specialization decreases predation on a marine amphipod: an herbivore in plant's clothing. Ecology 71:733-743.

Hay, M. E., J. E. Duffy, C. A. Pfister, and W. Fenical. 1987a. Chemical defenses against different marine herbivores: are amphipods insect equivalents? Ecology 68:1567-1580.

Hay, M. E., and W. Fenical. 1992. Chemical mediation of seaweed-herbivore interactions. Pages 319-337 in D. M. John, S. J. Hawkins, and J. H. Price, editors. Plant-animal interactions in the marine benthos. Systematics Association Special Volume 46. Clarendon, Oxford, England.

Hay, M. E., W. Fenical, and K. Gustafson. 1987b. Chemical defense against diverse coral-reef herbivores. Ecology 68 : 1581-1591. 
Hay, M. E., Q. E. Kappel, and W. Fenical. 1994. Synergisms in plant defenses against herbivores: interactions of chemistry, calcification, and plant quality. Ecology 75:17141726.

Hay, M. E., P. E. Renaud, and W. Fenical. 1988. Large mobile versus small sedentary herbivores and their resistance to seaweed chemical defenses. Oecologia 75:246-252.

Hay, M. E., and P. D. Steinberg. 1992. The chemical ecology of plant-herbivore interactions in marine versus terrestrial communities. Pages 371-413 in G. A. Rosenthal and M. R. Berenbaum, editors. Herbivores: their interactions with secondary plant metabolites. Second edition. Volume II. Evolutionary and ecological processes. Academic Press, San Diego, California, USA.

Hay, M. E., and J. P. Sutherland. 1988. The ecology of rubble structures of the South Atlantic Bight: a community profile. United States Fish and Wildlife Service Biological Report 85(7.20).

Hay, M. E., and P. R. Taylor. 1985. Competition between herbivorous fishes and urchins on Caribbean reefs. Oecologia 65:591-598.

Hughes, R. N., and C. J. Gliddon. 1991. Marine plants and their herbivores: coevolutionary myth and precarious mutualisms. Philosophical Transactions of the Royal Society of London B 333:231-239.

Jermy, T. 1984. Evolution of insect/hostplant relationships. American Naturalist 124:609-630.

John, D. M., S. J. Hawkins, and J. H. Price. 1992. Plantanimal interactions in the marine benthos. Systematics Association Special Volume 46. Clarendon Press, Oxford, England.

Johnson, C. R., and K. H. Mann. 1986. The crustose coralline alga Phymatolithon, Foslie inhibits overgrowth of seaweeds without relying on herbivores. Journal of Experimental Marine Biology and Ecology 96:127-146.

Keats, D. W., A. Groener, and Y. M. Chamberlain. 1993. Cell sloughing in the littoral zone coralline alga, Spongites yendoi (Foslie) Chamberlain (Corallinales, Rhodophyta). Phycologia 32:143-150.

Kennish, M. J. 1989. Practical handbook of marine science. CRC Press, Boca Raton, Florida, USA.

Lewis, S. M. 1986. The role of herbivorous fishes in the organization of a Caribbean reef community. Ecological Monographs 56:183-200.

Littler, M. M., P. R. Taylor, and D. S. Littler. 1983. Algal resistance to herbivory on a Caribbean barrier reef. Coral Reefs 2:111-118.

Lubchenco, J. 1980. Algal zonation in the New England rocky intertidal community: an experimental analysis. Ecology 61:333-344.

Lubchenco, J., and S. D. Gaines. 1981. A unified approach to marine plant-herbivore interactions. I. Populations and communities. Annual Review of Ecology and Systematics 12:405-437.

Maki, J. S., D. Rittschof, A. R. Schmidt, A. G. Snyder, and R. Mitchell. 1989. Factors controlling attachment of bryozoan larvae: a comparison of bacterial films and unfilmed surfaces. Biological Bulletin 177:295-302.

Masaki, T., D. Fujita, and N. T. Hagen. 1984. The surface ultrastructure and epithelium shedding of crustose coralline algae in a 'Isoyaki' area of southwestern Hokkaido, Japan. Hydrobiologica 116/117:218-223.

Morrison, D. 1988. Comparing fish and urchin grazing in shallow and deeper coral reef algal communities. Ecology 69:1367-1382.

Morse, A. N. C. 1992. Role of algae in the recruitment of marine invertebrate larvae. Pages 385-403 in D. M. John, S. J. Hawkins, and J. H. Price, editors. Systematics Association Special Volume 46. Clarendon, Oxford, England. Moss, B. L. 1982. The control of epiphytes by Halidrys siliquosa (L.) Lyngb. (Phaeophyta, Cystoseiraceae). Phycologia 21:185-191.

Orth, R. J. and J. van Montfrans. 1984. Epiphyte-seagrass relationships with an emphasis on the role of micrograzing: a review. Aquatic Botany 18:43-69.

Paul, V. J. 1992. Ecological roles of marine natural products. Comstock, Ithaca, New York, USA.

Paul, V. J., and M. E. Hay. 1986. Seaweed susceptibility to herbivory: chemical and morphological correlates. Marine Ecology Progress Series 33:255-264.

Pawlik, J. R. 199.2. Chemical ecology of the settlement of benthic marine invertebrates. Oceanography and Marine Biology Annual Review 30:273-335.

Peterson, C. H., and P. E. Renaud. 1989. Analysis of feeding preference experiments. Oecologia 80:82-86.

Rittschof, D., and J. D. Costlow. 1989. Bryozoan and barnacle settlement in relation to initial surface wettability: a comparison of field and laboratory studies. Pages 411-416 in J. D. Ros, editor. Topics in marine biology: proceedings of the 22nd European marine biological symposium. Instituto de Ciencias del Mar, Barcelona, Spain.

Rosenthal, G. A., and M. R. Berenbaum. 1992. Herbivores: their interaction with secondary plant metabolites. Second edition. Volume II. Evolutionary and ecological processes. Academic Press, San Diego, California, USA.

Rosenthal, G. A., and D. H. Janzen. 1979. Herbivores: their interaction with secondary plant metabolites. Academic Press, New York, New York, USA.

SAS. 1985. SAS user's guide: statistics. Version 5 edition. SAS Institute, Cary, North Carolina, USA.

Sieburth, J. M., and J. T. Conover. 1965. Sargassum tannin, an antibiotic which retards fouling. Nature 208:52-53.

Singer, M. C., and C. Parmesan. 1993. Sources of variations in patterns of plant-insect association. Nature 361:251-253.

Sokal, R. R., and F. J. Rolf. 1983. Biometry. W. H. Freeman, New York, New York, USA.

Spencer, K. C. 1988. Chemical mediation of coevolution. Academic Press, New York, New York, USA.

Steneck, R. S. 1982. A limpet-coralline alga association: adaptations and defenses between a selective herbivore and its prey. Ecology 63:507-522.

. 1983. Escalating herbivory and resulting adaptive trends in calcareous algal crusts. Paleobiology 9:44-61.

1986. The ecology of coralline algal crusts: convergent patterns and adaptive strategies. Annual Review of Ecology and Systematics 17:273-303.

- 1990. Herbivory and the evolution of nongeniculate coralline algae (Rhodophyta, Corallinales) in the North Atlantic and North Pacific. Evolutionary biogeography of the marine algae of the North Atlantic. NATO Advanced Science Institutes Series G 22:107-129.

- 1992. Plant-herbivore coevolution: a reappraisal from the marine realm and its fossil record. Pages 477491 in D. M. John, S. J. Hawkins, and J. H. Price, editors. Plant-animal interactions in the marine benthos. Systematics Association Special Volume 46. Clarendon, Oxford, England.

Strong, D. R., J. H. Lawton, and T. R. E. Southwood. 1984. Insects on plants: community patterns and mechanisms. Blackwell Scientific, Oxford, England.

Thompson, J. N., and J. J. Burdon. 1992. Gene-for-gene coevolution between plants and parasites. Nature 360:121125.

Thompson, J. N., W. Wehling, and R. Podolsky. 1990. Evolutionary genetics of host use in swallowtail butterflies. Nature 344:148-150.

Vermeij, G. J. 1983. Intimate association and coevolution in the sea. Pages 311-327 in D. J. Futuyma and M. Slatkin, editors. Coevolution. Sinauer, Sunderland, Massachusetts, USA. 
1992. Time of origin and biogeographical history of specialized relationships between northern marine plants and herbivorous molluscs. Evolution 46:657-664.

Wahl, M. 1989. Marine epibiosis. I. Fouling and antifouling: some basic aspects. Marine Ecology Progress Series 58: 175-189.

Williams, G. A., and R. Seed. 1992. Interactions between macrofaunal epiphytes and their host algae. Pages 189-211 in D. M. John, S. J. Hawkins, and J. H. Price, editors. Plant- animal interactions in the marine benthos. Systematics Association Special Volume 46. Clarendon, Oxford, England. Wylie, C. R., and V. J. Paul. 1988. Feeding preference of the surgeonfish Zebrasoma flavescens in relation to chemical defenses of tropical algae. Marine Ecology Progress Series 45:23-32.

Zucker, W. V. 1983. Tannins: does structure determine function? an ecological perspective. American Naturalist 121: 335-365. 